\title{
Dankadressen anläßlich der Verleihung der Karl-Hansen-Medaille 1999
}

\author{
30 Jahre lang hat sich das Ehepaar Rother gemeinsam der \\ Erforschung des Komplementsystems verschrieben. Am Anfang \\ waren 4 Faktoren bekannt, jetzt sind es mindestens 30 - eines der \\ Hauptverdienste des Ehepaares, deren Forschungsergebnisse \\ heute Eingang in die einschlägigen Lehrbücher gefunden haben. \\ In ihren Dankesadressen ließen Klaus und Ursula Rother ihre \\ wissenschaftliche Arbeit Revue passieren. Doch auch das \\ Persönliche sollte nicht zu kurz kommen.
}

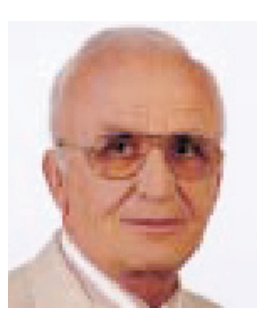

„Karl Hansen hatte sich 1957 entschlossen, die Neuauflage seines Standardwerkes ,Allergie' in Einzelkapitel zu fassen. Für den Beitrag ,Niere' fiel die Wahl auf die Sarre'sche Nierenklinik in Freiburg und dort auf den jungen Assistenten Rother." So begann Klaus Rother seine Dankesrede nach Entgegennahme der Karl-Hansen-Medaille 1999. „Seither steht das Bild der Persönlichkeit des großen Hansen vor mir. In Bescheidenheit nehme ich die heutige Auszeichnung nach seinem Namen an.“

Nicht ganz leicht fiel es dem Jungwissenschaftler damals, in einer Zeit der ebenso diffusen wie emotional geführten Terminologiedebatten in die noch recht nebulöse Theorie der allergischen Erkrankungen der Niere einzuführen - zumal allergische Hämaturien selten sind.

Doch war damit endgültig das Interesse geweckt für seine Forschungen an C-defekten Tieren, dessen Fazit nach nunmehr 40 Jahren Klaus Rother 1998 in einer Monografie zusammenfaßte. Rother: „Uns gelang 1. die weitgehende Aufklärung der primären C-Funktionen in der Entzündungspathogenese, 2. der Nachweis der C-induzierten Freisetzung eines Netzwerkes von
Mediatoren, darunter der Leukotriene, Prostaglandine, Thromboxane u.a. mit fördernder und dämpfender Wirkung und 3. - und dies scheint mir von besonderem Gewicht - der Nachweis der Redundanz oft paralleler Reaktionswege."

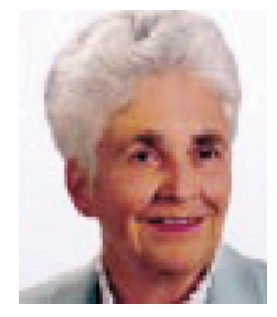

Die Forschungsergebnisse von Klaus Rother sind auch die Ergebnisse seiner Gattin Ursula Rother. Sie entdeckte Ende der 50er Jahre bei einem Forschungsaufenthalt in den USA ihre Liebe zur Immunologie. Und egal, wo gerade Wissenschaft betrieben wurde, die Arbeitsteilung war klar: Klaus Rother war „Chef" von Kliniken und Instituten mit allen organisatorisch-repräsentativen Pflichten -, während sich Ursula Rother um die Laborarbeit kümmerte.

Ursula Rother: „Ich glaube, daß ein solches Team, bei dem beide an einem Strang ziehen, eine gute Sache ist, die allerdings von den meisten Universitäten nicht gerne gesehen wird. Es hat mich auch nicht gestört, daß mein Part mehr im Verborgenen lag. Ich habe die Ehrungen meines Mannes immer mit genossen. Heute aber nun, lange nach der Pensionierung, empfangen wir eine Ehrung als Team, und darüber freue ich mich natürlich besonders." 